\title{
Adolescent Health needs - Special attention and a New Subspeciality - Adolescent Medicine
}

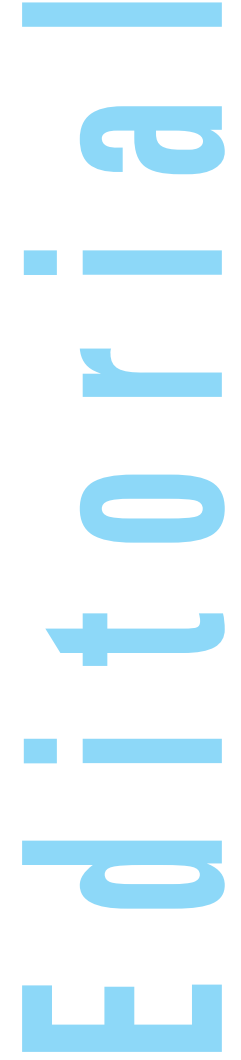

${ }^{1}$ Prof. Dr. B H Nazma Yasmeen MBBS, MCPS, MD (Paed) Editor Northern International Medical College Journal

\section{Professor and Head} Dept. of Paediatrics Northern International Medical College, Dhaka e-mail :

prof.nazma.yasmeen@gmail.com

\section{B H N Yasmeen ${ }^{1}$}

The word "adolescence" is derived from a Latin word adolescere, which means 'to grow up' i.e. to grow into adulthood. ${ }^{1}$ WHO defines individuals in the age group of 10 to 19 years as adolescents. ${ }^{2}$ Worldwide, there are about 1.2 billion adolescents today. ${ }^{3}$ And there are about 360 million adolescents comprising about $20 \%$ of the population in the countries of the SouthEast Asia Region. ${ }^{2}$ In Bangladesh, there are now 36 million adolescents, making up $22 \%$ of the total population. ${ }^{4}$

Adolescence is the period when an individual is no longer a child, but not yet an adult, it is the bridge between childhood and adulthood. In other words, it is the transition period from the child to the adulthood of a person. Adolescent period begins with the onset of puberty. ${ }^{5} \mathrm{~A}$ very dynamic and dramatic physical, psychological, and social changes occurs in this period. In general, girls enter puberty between the ages of 8 and 13, and boys between 9 and 14 years. ${ }^{6}$

WHO describes "adolescence" as a phase rather than a fixed time period because it is an extraordinary phase of development of an individual in many aspects e.g. rapid physical growth and development of sexual and reproductive maturity; adult mental processes and adult identity; and relative independence of socio-economic and emotional dependence. ${ }^{6}$

During this period, the mind gradually becomes ready for more abstract thinking. Social relationships spread from family centered to a wider field, in which peers and other adults come to play significant roles in the adolescent's life.

Adolescence is divided into early, middle, and late periods. ${ }^{6}$

\begin{tabular}{|l|l|l|} 
periods & age groups & \multicolumn{1}{|c|}{ criteria } \\
\hline Early adolescence & $10-13$ years & $\begin{array}{l}\text { growth spurt and secondary sexual } \\
\text { characters developed }\end{array}$ \\
\hline Mid adolescence & $14-16$ years & $\begin{array}{l}\text { independence and identity, } \\
\text { experimentation and } \\
\text { relationship with peers and opposite } \\
\text { sex developed }\end{array}$ \\
\hline Late adolescence & $17-19$ years & $\begin{array}{l}\text { nearly achieved adult physical and } \\
\text { mental characters }\end{array}$ \\
\hline $\begin{array}{l}|l| \\
\text { the changes occurring during this period may not correspond neatly } \\
\text { with precise ages }\end{array}$
\end{tabular}

As there are multidimensional changes occuring during this period, optimum healthcare is essential to develop their full potential. Neglecting the adolescence health care need, it would not at all be possible to ensure their proper growth and development during this transition time. Besides this, some adolescents may develop health problems, or behavioral problems, that could lead to a disease or even premature death. All these health issues of the adolescent needs special attention.

Like other developing countries, the health care providers of Bangladesh also frequently address the following health problems of the adolescent.

\section{Malnutrition}

As adolescence is the period of rapid growth and sexual maturation, optimal nutrition is a prerequisite for achieving full growth potential. Therefore, inadequate nutrition hampers this process both in boys and girls. Adolescent boys require more energy than girls because they have more muscles, and their body is larger. Adolescent girls need more iron for increased growth, and menstruation and iron deficiency are common among them.

Inadequate nutrition during adolescence can reduce their work capacity and productivity of recent and also later life. Moreover, a malnourished adolescent mother is at the risk of developing complications during pregnancy and there will be more possibility to giving birth to a low-birth-weight baby. ${ }^{7}$ 


\section{Delayed or precocious puberty and menstrual disorders}

These are the relatively common endocrine problems among adolescent girls encountered by the health professionals specially gynaecologist or paediatrician.

\section{Acne}

Almost all adolescent boys and girls get acne. It is so common that it is considered as a normal part of puberty and it is not a serious health problem. But knowing that does not always make it easier to accept it, when one's face is affected by acne. Because severe acne can cause permanent scars and it can also damage self-esteem of an adolescent.

\section{Eating disorders}

Eating disorders are dramatically increased in frequency over the past 3 decades among adolescents. It is the 3 rd most common chronic illness in adolescent girls. ${ }^{8}$ with an incidence of up to $5 \% .{ }^{9}$ Anorexia nervosa and bulimia nervosa are the 2 major types of the eating disorders found among them.

\section{Internet addiction}

Globally approximately $49 \%$ of teenagers, have access to the Internet. ${ }^{10}$ Initially internet induces pleasure to most of the users. Then is he or she continues to use it for more and more hours and experiences withdrawal symptoms (depression, cravings, insomnia, and irritability) upon discontinuing the internet, then it could be labeled as internet addiction. Because addiction is manifested in both physical and psychological dependence. ${ }^{11}$ As they may have limited coping skills, internet may be a convenient way for the adolescents to deal with the tension. ${ }^{12}$ By using internet many of them are willing to engage in the bullying or harassing of others, gain access to pornography and find opportunities to be rebellious toward parents or guardians. ${ }^{13}$

\section{High risk behaviors}

High risk behaviors include substance abuse, interpersonal violence, suicide etc. These are the primary causes of morbidity and mortality in many of the adolescent patients.

\section{a) Substance Abuse}

During adolescence people are most likely to begin abusing drugs like tobacco, alcohol, and illegal prescription drugs. The reasons for using these substances, includes the desire for new experiences, an attempt to deal with problems or perform better in school, and simple peer pressure etc. Their normal developmental drives are new excitements which will be fulfilled by trying drugs. But it is an unhealthy way which has very serious long-term consequences (drug addiction, even premature death) due to continuous use or overdose. ${ }^{14}$ Harmful substance use in adolescent period will increase the risk of cancers, cardiovascular diseases, and respiratory illnesses later in life. ${ }^{15}$

\section{b) Interpersonal violence}

Interpersonal violence is a form of intentional injury, frequency of which is increasing among adolescents. Girls are especially being victimized. ${ }^{15}$ Recent news in Bangladesh showed that boys are also victims of violence (Adolescent gang star of Uttara, Dhaka and Kushtia are the example).

\section{c) Suicide}

Suicide is 1 of the 3 leading causes of death of adolescents. Suicide rates is rising faster among adolescents. Each year about 90,000 suicides are committed by adolescents and for every completed attempt of suicide, there are at least 40 unsuccessful attempts. ${ }^{16}$

\section{Unintentional injuries}

Unintentional injuries are the leading cause of death among young people, especially traffic accidents. Each year about 195,000 adolescents killed in traffic accidents, more than $60 \%$ are boys (WHO GPE 2000). Drowning, poisoning, fire burns are also the next common causes of unintentional injuries in the developing countries.

\section{Early marriage, pregnancy and delivery of LBW baby}

Like most of the developing countries, Bangladesh also has high rate of child marriage. Our adolescent girls face the risks of early pregnancies, violence, and lack of nutrition. Here about $53 \%$ adolescent girls were married before the age of $18 .{ }^{4}$ Besides early unwanted pregnancy they may sometimes suffer from sexually transmitted infections (e.g., HIV).
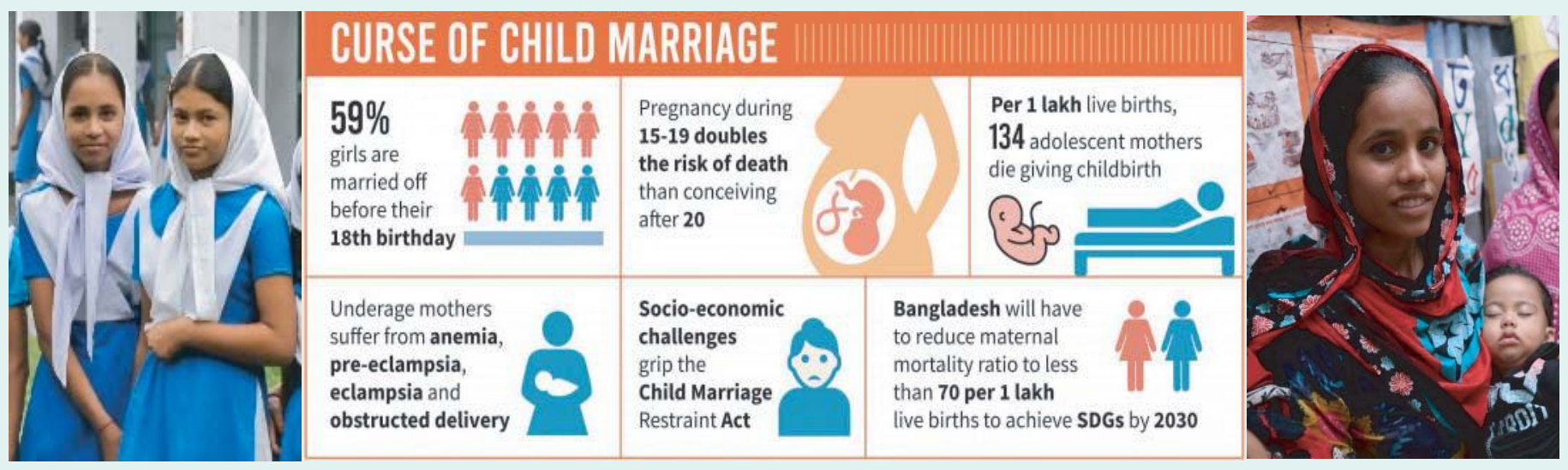
Adolescent mothers are at risk of complications both during pregnancy and during delivery. Among them unsafe abortions are estimated at 2.5 million a year, representing $14 \%$ of all unsafe abortions. (WHO, RHR, 2002). Anemia in adolescence pregnancy is common and causes maternal morbidity and mortality as well as poor birth outcomes e.g., still birth, low birth weight (LBW), and prematurity. ${ }^{25}$

\section{Certain mental illness}

Adolescent people are often vulnerable to different stresses (challenges of growing up and exposure to risky behaviors) that contribute to mental illness and some mental health problems first appear at that time (depression, schizophrenia etc). Early identification and management are crucial for a successful and long-lasting recovery in such cases. ${ }^{16}$

\section{Sexual abuse}

In the developing countries most of the sexual abuse cases of adolescents remain unreported. Therefore, it is difficult to collect reliable data on this issue. ${ }^{17,18}$ In fact, a great majority of sexually abused adolescent victims were girls but a large number of boys also experienced sexual abuse. ${ }^{19}$ There may be a long term traumatic psychological effect depending on the severity and persistence of the sexual abuse. ${ }^{20}$ The most common psychological problems associated with childhood sexual abuse are depression, PTSD, suicide attempts, low selfesteem and even somatic problems etc. ${ }^{21-24}$

\section{Chronic and endemic diseases}

Chronic conditions such as asthma, epilepsy, cystic fibrosis, juvenile diabetes and haemoglobinopathies etc. could adversely affect adolescent growth and development.

It can be a challenge to manage these conditions in adolescents within the context of all other changes that are taking place during this period. Endemic diseases such as malaria and tuberculosis are among the 10 major causes of death in adolescents. ${ }^{26}$

The management of all these health problems require comprehensive care and support, addressing both medical and psychosocial issues. In USA, the first medical symposium on adolescence was held in 1941 by American Academy of Pediatrics (AAP). Then the first inpatient department and academic training program in adolescent medicine was arranged at Boston Children's Hospital by 1950 s. $^{28}$ In the $1960 \mathrm{~s}$ adolescent medicine training programs with comprehensive inpatient, outpatient, and psychosocial support services were developed by the support of the federal government. Subsequently, by 1968 the Society for Adolescent Medicine was formed. ${ }^{2}$ Later in 1979, the AAP formally provided continuing medical education in adolescent medicine for the practicing pediatrician. In 1994, the American Board of Pediatrics administered the first examination in adolescent medicine and in 1998 the Accreditation Council on Graduate Medical Education, through its Pediatric Residency Review Committee process, accredited 16 adolescent medicine fellowship training programs. $^{29}$

\section{Where are we now?}

Our general Paediatrician covers all child from birth to infancy, childhood, and adolescence. Though Neonatology has been already stablished as a subspeciality, but still Adolescent medicine is far back behind. In our country adolescents and their families also have extremely limited awareness of their health needs. This includes information on nutrition, and psycho-social counselling and reproductive health as well as preventable causes of adolescent death.

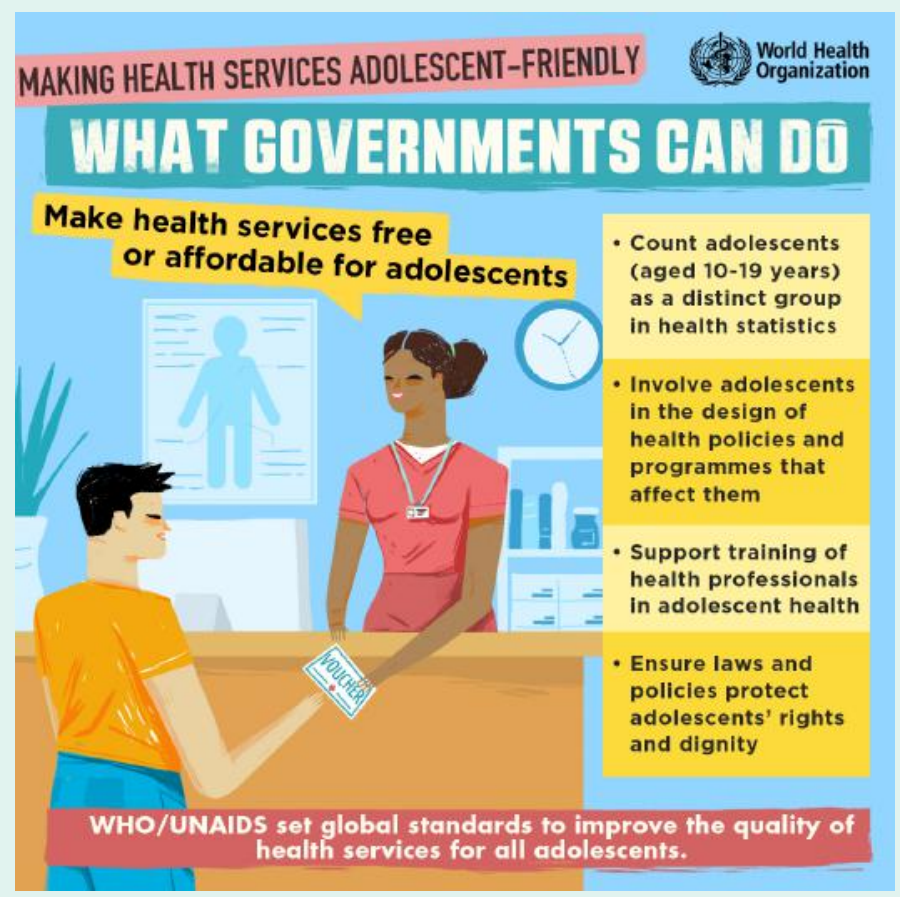

Today's adolescents are tomorrow's parents, teachers, and leaders. Therefore, now it is the time to develop a subspeciality on Adolescent Medicine in our country to address all these health problems. Adolescent medicine is a medical subspecialty that focuses on care of patients who are in the adolescent period of development. ${ }^{27}$

In our country at this initial stage of Adolescent medicine we need multidisciplinary health professionals, at least a combination of general Paediatrician, Nutritionist, Endocrinologist, Psychiatrist, Psychologist, Counselor and Gynaecologist, until Adolescent Medicine specialist would be developed. Undoubtedly it will bring many challenges to face the complex medical, developmental and psychosocial issues of the adolescent patient. But profound opportunities are waiting to support the needs of this patient group. 
Physicians and govt. policy makers should understand that special attention is needed for adolescent health to reduce the morbidity and mortality during adolescence and also in their later life. Finally, it will maximize their opportunity to develop their full potential and to contribute the best to our society.

\section{References}

1. Macmillan Dictionary for Students Macmillan, Pan Ltd. (1981), page 14, 456. Retrieved July 15, 2010.

2. https://www.who.int/health-topics/adolescent-health/

3. United Nations, Department of Economic and Social Affairs, Population Division, World Population Prospects: The 2008 revision, <www.esa.un.org/ unpd/wpp2008/index.htm>, accessed October 2010; and UNICEF global databases, accessed October 2010

4. https://www.unicef.org/bangladesh/en/improving-health-adolescents

5. https://en.wikipedia.org > wiki > Puberty

6. https://www.who.int/maternal_child_adolescent/documents/9241591269/en/ WHO Orientation programme on adolescent health for health-care providersHandbook

7. https://vikaspedia.in/health/women-health/adolescent-health-1/managementof-adolescent-health/nutritional-needs-of-adolescents

8. 1. Whitaker $\mathrm{AH}$. An epidemiological study of anorectic and bulimic symptoms in adolescent girls: Implications for pediatricians. Pediatr Ann. 1992; 21:752-9. [PubMed] [Google Scholar]

9. 2. Stein DM. The prevalence of bulimia: A review of the empirical research. J Nutr Educ. 1991;23:205-13. [Google Scholar]

10. Skinner H. BiscopeS.Poland B. Quality of internet access.Soc Sci Med. 2003; 57: 875-880Scopus (100)PubMedCrossrefGoogle Scholar

11. McMurran M. The psychology of addiction. Taylor \& Francis; 1994.

12. 12. Kim K, Ryu E, Chon MY, Yeun EJ, Choi SY, Seo JS, Nam BW. Internet addiction in Korean adolescents and its relation to depression and suicidal ideation: a questionnaire survey. Int J Nurs Stud 2006;43(2):185-92.

13. 13. Young KS. Internet addiction: The emergence of a new clinical disorder. CyberpsycholBehav 1998;1(3):237-44.

14. https://www.drugabuse.gov/publications/principles-adolescent-substanceuse-disorder-treatment-research-based-guide/introduction

15. Klerman LV. The influence of economic factors on health-related behaviour in adolescents.In: Millstein SG, Petersen AC, Nightingale EO, eds. Promoting the health of adolescents. New directions for the twenty-first century. New York, Oxford University Press, 1993

16. Senderowitz J. Adolescent health: reassessing the passage to adulthood. Washington, DC, World Bank, 1995 (World Bank Discussion Paper N272).

17. Kogan SM. Disclosing unwanted sexual experiences: results from a national sample of adolescent women. Child Abuse Negl. 2004; 28:147-165. http:// dx.doi.org/10.1016/j.chiabu.2003.09.014. [PubMed] [Google Scholar]
18. Priebe G, Svedin CG. Child sexual abuse is largely hidden from the adult society. An epidemiological study of adolescents' disclosures. Child Abuse Negl. 2008;32:1095-1108. http://dx.doi.org/10.1016/j.chiabu.2008.04.001. [PubMed] [Google Scholar]

19. Fis NP, Arman A, Kalaca S, Berkem M. Psychiatric evaluation of sexual abuse cases: A clinical representative sample from Turkey. Child Youth Serv Rev. 2010;32:1285-1290. http://dx.doi.org/10.1016/j.childyouth.2010.04. 020. [Google Scholar]

20.Molnar BE, Buka SL, Kessler RC. Child sexual abuse and subsequent psychopathology: Results from the national comorbidity survey. Am J Public Health. 2001;91:753-760. http://dx.doi.org/10.2105/AJPH.91.5.753. [PMC free article] [PubMed] [Google Scholar]

21.Briere JN, Elliott DM. Immediate and long-term impacts of child sexual abuse. Future Child. 1994;4:54-69. http://dx.doi.org/10.2307/1602523. [PubMed] [Google Scholar]

22. Avery L, Massat CR, Lundy M. Posttraumatic stress and mental health functioning of sexually abused children. Child Adolesc Social Work J. 2000;17:1934. http://dx.doi.org/10.1023/A:1007563509000. [Google Scholar]

23. Paolucci EO, Genuis ML, Violato C. A meta-analysis of the published research on the effects of child sexual abuse. J Psychol. 2001; 135:17-36. http://dx.doi.org/10.1080/00223980109603677. [PubMed] [Google Scholar]

24. Oates RK, O'Toole BI, Lynch DL, Stern A, Cooney G. Stability and change in outcomes for sexually abused children. J Am Acad Child Adolesc Psychiatry. 1994;33:945-953. http://dx.doi.org/10.1097/00004583199409000-00003. [PubMed] [Google Scholar]

25. N. Kozuki, A. C. Lee, and J. Katz, "Moderate to severe, but not mild, maternal anemia is associated with increased risk of small-for-gestationalage outcomes," Journal of Nutrition, vol. 142, no. 2, pp. 358-362, 2012.View at: Publisher Site | Google Scholar

26. A picture of health. A review and annotated bibliography of the health of young people in developing countries. WHO Geneva, 1995 (document WHO/FHE/ADH/95.14).

27. Rieder S, Alderman EM, Cohen, MI (Feb 2011). "Adolescent Medicine: Emergence of a New Specialty". AMA Journal of Ethics. doi:10.1001/ virtualmentor.2005.7.3.msoc1-0503

28. Heald F. History of adolescent medicine: a personal perspective. In: Friedman SB, Fisher M, Schonberg SK, eds. Comprehensive Adolescent Health Care. 1st ed. St. Louis, Mo: Quality Medical Publishing; 1992: XVXVIII. Google Scholar

29.https://journalofethics.ama-assn.org/article/adolescent-medicine-emergencenew-specialty/2005-03 